\title{
Nylon-flocked swab collection method better predicts high-grade AIN than does dacron swab method
}

\author{
Dorothy Wiley ${ }^{1 *}$, Robert Bolan², Alen Voskanian³ ${ }^{3}$ Stephen Young ${ }^{4}$, David Elashoff ${ }^{3}$, Hilary Hsu', \\ Emmanuel Masongsong ${ }^{5}$, Provaboti Barman ${ }^{1}$, Roger Detels ${ }^{6}$ \\ From 13th International Conference on Malignancies in AIDS and Other Acquired Immunodeficiencies \\ (ICMAOI)
}

Bethesda, MD, USA. 7-8 November 2011

\section{Background}

Invasive anal cancer (IAC) is a health crisis for gay, bisexual, transgender, and other men who have sex with men (MSM) who show a 20-40 fold higher risk for disease, especially if infected by HIV despite the introduction of HAART. Human papillomaviruses (HPV) that cause invasive cervical cancers (ICC) in women appear responsible for the majority of IACs. Although cervical cytology using Pap test has reduced ICC incidence by $\sim 70 \%$, anal Pap test only shows modest sensitivity and poor-to-modest specificity for detecting high-grade anal intraepithelial neoplasias (HG-AIN). Currently anal Pap testing using Dacron swab is recommended annually and biennially for HIV-infected and uninfected MSM, respectively. Swabs are inserted blindly through the anus, and ASCUS, low- and high-grade dysplasias (LG-, HG-SIL) are evaluated using high resolution anoscopy (HRA).

\section{Material and methods}

Dacron-swab cytology specimens were collected first using standard procedures; subsequently, Nylon Flocked (NF)swabs were collected through an anoscope inserted just beyond the verge. Swabs were approximated to the canal, rotated slowly while withdrawn, and placed into preservatives. HRA, with medical biopsy, where indicated, was performed by experienced clinicians. Pathologists evaluated cytology using the Bethesda Classification System, and histology using the International Classification of Diseases for

\footnotetext{
* Correspondence: dwiley@ucla.edu

${ }^{1}$ School of Nursing, UCLA, Los Angeles, CA, USA

Full list of author information is available at the end of the article
}

Oncology. HPV genotypes were assessed from cytology specimens using Linear Array (Roche Diagnostic Laboratories, Pleasanton, CA).

\section{Results}

Among 69 specimens obtained, 10 Dacron and 8 NFspecimens were inadequate for cytological evaluation: $14.5 \%$ and $11.6 \%$. Sensitivity for HG-AIN and specificity were higher for cytology using NF- than Dacron swabs: $82 \%(66-98 \%)$ and 59\% (44-74\%), versus 55\% (34-76\%) and $49 \%$ (33-65\%), respectively. Multivariate analyses showed NF-swab specimens more accurately predicted HG-AIN than Dacron swabs. Specimens showing either ASCUS /LG-SIL, or HG-SIL on NF-swab were 10 (1.9, $52.0)$ and $5.3(0.4,74)$ times more likely than unaffected specimens similarly collected to predict HG-AIN; whereas, Dacron-swab specimens using these cut-points showed no statistically greater risk for HG-AIN on histology, $\mathrm{OR}=0.4(0.1,2.3)$ and $\mathrm{OR}=4.7(0.4,61.5)$, respectively. These relationships persisted after controlling for age, HIV-infection, duration of infection, and multiple observations $(n=7)$.

\section{Conclusions}

Cytology specimens using Dacron swab blindly inserted through the anus less often predicted HG-AIN than did NF-swab specimen used in conjunction with an anoscope to guide placement.

\footnotetext{
Author details

${ }^{1}$ School of Nursing, UCLA, Los Angeles, CA, USA. ${ }^{2}$ L.A. Gay \& Lesbian Center, Los Angeles, CA, USA. ${ }^{3}$ School of Medicine, UCLA, Los Angeles, CA, USA.
} ${ }^{4}$ Tricore Diagnostic Laboratories, University of New Mexico, Albuquerque, 
Published: 19 April 2012

doi:10.1186/1750-9378-7-S1-P49

Cite this article as: Wiley et al: Nylon-flocked swab collection method

better predicts high-grade AIN than does dacron swab method.

Infectious Agents and Cancer 2012 7(Suppl 1):P49.

Submit your next manuscript to BioMed Central and take full advantage of:

- Convenient online submission

- Thorough peer review

- No space constraints or color figure charges

- Immediate publication on acceptance

- Inclusion in PubMed, CAS, Scopus and Google Scholar

- Research which is freely available for redistribution

Submit your manuscript at www.biomedcentral.com/submit
() Biomed Central 